eCommons@AKU

January 2014

\title{
Treatment of chronic hepatitis D patients with pegylated interferon: a real-world experience
}

Zaigham Abbas

Aga Khan University, zaigham.abbas@aku.edu

Mohammad S. Memon

Hammad Mithani

Wasim Jafri

Aga Khan University, wasim.jafri@aku.edu

Saeed Hamid

Aga Khan University, saeed.hamid@aku.edu

Follow this and additional works at: https://ecommons.aku.edu/ pakistan_fhs_mc_med_gastroenterol

Part of the Gastroenterology Commons

\section{Recommended Citation}

Abbas, Z., Memon, M. S., Mithani, H., Jafri, W., Hamid, S. (2014). Treatment of chronic hepatitis D patients with pegylated interferon: a real-world experience. Antiviral Therapy, 19(5), 463-468.

Available at: https://ecommons.aku.edu/pakistan_fhs_mc_med_gastroenterol/232 


\section{Treatment of chronic hepatitis $D$ patients with pegylated interferon: a real world experience}

Zaigham Abbas, Mohammad Sadik Memon, Hammad Mithani, Wasim Jafri, Saeed Hamid

Antiviral Therapy 2014; 10.3851/IMP2728

Submission date

8th November 2013

Acceptance date 19th December 2013

Publication date 14th January 2014

This provisional PDF matches the article and figures as they appeared upon acceptance.

Copyedited and fully formatted PDF and full text (HTML) versions will be made available soon.

For information about publishing your article in Antiviral Therapy go to http://www.intmedpress.com/index.cfm?pid=12 


\section{Original article}

\section{Treatment of chronic hepatitis D patients with pegylated interferon: a real world experience}

Zaigham Abbas ${ }^{1,2 \star}$, Mohammad Sadik Memon ${ }^{3}$, Hammad Mithani², Wasim Jafri', Saeed Hamid ${ }^{1}$

${ }^{1}$ Department of Medicine, The Aga Khan University Hospital, Karachi, Pakistan

${ }^{2} \mathrm{OMI}$ Hospital, Karachi, Pakistan

${ }^{3}$ Isra University, Hyderabad, Pakistan

*Corresponding author e-mail: drzabbas@gmail.com

\section{ABSTRACT}

Background: Published experience of treating chronic hepatitis D patients with pegylated interferon (PEG-IFN) alpha is limited. The aim of this study was to determine the efficacy of 48 weeks treatment with PEG-IFN in naïve patients outside the clinical trial setting in the real world.

Methods: Patients with chronic hepatitis D were treated with PEG-IFN. The primary end points were sustained clearance of HDV RNA and normal alanine aminotransferase (ALT) at 24 weeks post-treatment.

Results: Patients treated with PEG-IFN were 104; male 91, mean age $30.1 \pm$ 10.0 years (range 15-55). Cirrhosis was present in 41 patients. With an intention to treat analysis, end of treatment virological response (ETR) was achieved in $44(42.3 \%)$, normalization of ALT in $38(35 \%)$ and a combined response in $23(22.1 \%)$ patients. Sustained virological response (SVR) at 24 weeks post-treatment was seen in $24(23.1 \%)$ patients each for the virological and biochemical responses and in $13(12.5 \%)$ as combined response. Both ETR and SVR were associated with a negative HDV RNA at 24 weeks of treatment $(p=0.001$ and 0.000$)$. Detectable HDV RNA at this point had a positive predictive value of $0.95(0.85-0.99)$ for a detectable RNA at six months post treatment. End of treatment biological response i.e. normal ALT at the end of treatment was also a predictor of ETR and SVR ( $p$ $=0.004$ and 0.041).

Conclusions: Treatment with PEG-IFN for hepatitis D is of limited efficacy. Detectable HDV RNA at 24 weeks of treatment is a predictor for a failed SVR.

Accepted 19 December 2013, published online 14 January 2014 


\section{Abbreviations:}

HDV, hepatitis D virus; PEG-IFN, pegylated interferon alpha; ALT, alanine aminotransferase; RNA, ribonucleic acid; ETR, end of treatment virological response; SVR, sustained virological response; HBsAg, hepatitis B surface antigen; HCV, hepatitis C virus; HIV, human immunodeficiency virus; PCR, polymerase chain reaction; $\mathrm{HBeAg}$, hepatitis Be antigen

\section{INTRODUCTION}

HDV is a defective RNA agent needing the presence of HBV for its own replication [1]. Persistent HDV replication leads to cirrhosis and hepatocellular carcinoma at annual rates of $4 \%$ and $2.8 \%$ respectively [2]. This figure underscores the need to treat this infection. Unfortunately, there is no effective antiviral therapy available for the treatment of hepatitis $D$. The only established therapy for chronic delta hepatitis is interferon alpha, standard or pegylated, which has to be administered for at least 48 weeks [3].

A recent Cochrane review showed that therapy with standard interferons may result in an end of treatment virological and biochemical response in one third of patients but sustained virological response, judged by loss of HDV RNA from serum at six months, was seen in only $17.4 \%$ of patients. Histological improvement was seen in one-quarter of the patients [4].

The experience of using pegylated interferon (PEG-IFN) alpha in delta hepatitis is limited to a few studies. The treatment led to sustained elimination of HDV RNA in only about $20-25 \%$ of patients $[1,3]$. Its efficacy in a real world scenario is not known. The aim of this study was to determine the efficacy and safety of PEG-IFN given for 48 weeks for the treatment naïve patients with chronic hepatitis $D$ in real-world clinical setting.

\section{MATERIALS AND METHODS}

\section{Participants:}

All the patients with chronic hepatitis D who were treated with PEG-IFN alpha from 2009 to 2011 were considered for inclusion in this retrospective analysis. The patients hailed from three centers that were following the same algorithm to treat hepatitis D. The liver biopsy and PCR studies were done in a single center. Inclusion criteria were the patients of age between 18-60 years with chronic hepatitis $D$ and compensated liver disease, HBsAg reactive and anti-HDV antibody positive for at least 6 months, presence of HDV RNA in blood by PCR, alanine aminotransferase (ALT) levels more than the upper limit of normal (ULN), hemoglobin $\geq 10.0 \mathrm{gram} / \mathrm{dl}$, white blood cell count of $\geq 2.5 \times 10^{9} / \mathrm{L}$, neutrophils $\geq 1.5 \times 10^{9} / \mathrm{L}$, platelet $\geq 75 \times 10^{9} / \mathrm{L}$, and negative tests for hepatitis $\mathrm{C}$ virus (HCV) and human immunodeficiency virus (HIV). Exclusion criteria were the 
patients who had received antiviral therapy within the previous 6 months, evidence of other genetic, autoimmune or metabolic liver diseases, pregnant or breastfeeding women, alcohol abuse, uncontrolled psychiatric disease, severe chronic pulmonary, renal or cardiac diseases, bleeding disorders, elevated alpha-fetoprotein $>100 \mathrm{ng} / \mathrm{ml}$ and active or suspected cancer elsewhere in the body. Liver biopsy specimens were available only in 39 patients. Grading of inflammation and the staging of fibrosis was performed according to the Batt's and Ludwig's classification [5]. All the patients were managed by the usual standards of care. Local ethics committees did not find any objection in publication of the data.

\section{Treatment:}

All patients eligible for antiviral therapy were treated with PEG-IFN alpha 2a (Pegasys $\AA$, F. Hoffmann-La Roche Ltd, Basel) $180 \mu$ g subcutaneously per week or PEG-IFN alpha 2b (PegIntron®, Schering Plough Corp., Kenilworth, NJ) $1.5 \mu \mathrm{g} / \mathrm{kg}$ subcutaneous weekly in a weightbased dosing regimen. Patients were educated regarding administration of pegylated interferon, expected adverse events, schedule for laboratory monitoring, and clinic appointment.

\section{Outcomes:}

Primary end points were undetectable HDV-RNA levels (virological response) and normal ALT (biochemical response) at the end of 24 weeks of post treatment follow-up. Secondary end points were the normalization of ALT and HDV RNA-negativity at the end of treatment.

\section{Viral nucleic acids testing:}

Viral nucleic acids were isolated from patients' serum samples by High Pure Viral Ncleic Acid Kit, according to the manufacturer's instructions (Roche Diagnostics, USA). HBV DNA PCR qualitative analysis was performed by the Cobas Amplicor HBV Monitor (Roche Diagnostic Systems, Basel, Switzerland) with a lower detection limit of 500 copies/ml. For HDV RNA, qualitative test was based on the reverse transcription PCR of the target gene. Quantification of HDV RNA was done by real time PCR having a lower limit of detection of $500 \mathrm{IU} / \mathrm{ml}$.

\section{On-treatment evaluation:}

Patients were evaluated as outpatients for safety, tolerance and efficacy every 4 weeks during treatment until week 48 and then at 72 weeks during the follow-up period. At each visit complete blood count and biochemistry was assessed. HDV RNA was checked at screening, 24 weeks, end of treatment (48 weeks) and end of follow-up (24 weeks post treatment). Serum HBV DNA was tested at screening, week 48 , and end of follow-up. 


\section{Adverse events:}

Serious adverse events were defined as those that were fatal, life-threatening, required inpatient hospitalization or discontinuation of treatment. Non-serious adverse events and laboratory abnormalities leading to dose modifications and premature withdrawal from therapy were noted.

\section{Statistical Analysis:}

Intent-to-treat (ITT) efficacy analysis was conducted on all those subjects who were started on treatment $(n=104)$. Patients with missing values were considered as non-responders. Additional per protocol analysis was made on the population of patients who completed 48 weeks of therapy. Data were expressed as the number of subjects with percentages for nominal variables or means with standard deviation for continuous variables. Treatment factors associated with HDV RNA negativity at week 72 (24 weeks post-treatment) were assessed. The chi-square test and Fisher exact tests were used to compare categorical data. Continuous variables were evaluated using t-test or non-parametric test (Mann-Whitney $U$ - test). A two-tailed $p$ value $<0.05$ was required for statistical significance.

\section{RESULTS}

A total of 104 patients were treated and followed up between January 2009 and December 2011. These included 69 patients who received PEG-IFN alpha-2a (180 $\mu \mathrm{g}$ once weekly) and 35 patients who received PEG-IFN alpha-2b $(1.5 \mu \mathrm{g} / \mathrm{kg}$ once weekly). Male patients were 91 , mean age $30.1 \pm 10.0$ years (range 15-55). Demographic and baseline clinical characteristics of the patients are shown in Table 1.

Hepatitis $\mathrm{Be}$ antigen ( $\mathrm{HBeAg})$ was reactive in 29 (27.9\%) cases while the HBV DNA was detectable in 37 (35.6\%); 22 were HBeAg positive. Liver biopsy was available in only in 39 cases. Mild inflammation was seen in 1, moderate in 12 and severe in 26 patients. Stage of the disease was 1-2 in 30 and 3-4 in 9 patients. Cirrhosis of the liver as evident from histology, ultrasound or clinical examination was present in 41 (39.4\%) patients. One patient had diabetes and five were having arterial hypertension.

With an intention to treat analysis, clearance of HDV RNA at the end of treatment was achieved in 44 patients (42.3\%) and normalization of ALT in 38 (35\%). Both virological and biochemical responses were seen in $23(22.1 \%)$ patients. The efficacy of PEG-IFN was sustained in $24(23.1 \%)$ each in terms of virological and biochemical responses and in $13(12.5 \%)$ as a combined response at 24 weeks follow-up. This data included 2 patients who had detectable HDV RNA at the end of treatment but negative PCR six months post treatment. 
Publication: Antiviral Therapy; Type: Original article DOI: $10.3851 / \mathrm{IMP} 2728$

End of treatment virological response (ETR) and sustained virological response (SVR) at week 24 post-treatment was associated with negative HDV RNA at 24 weeks of treatment ( $p$ values 0.001 and 0.000 , risk ratio 2.29 (1.29-4.33) and 7.75 (1.98-47.16), odds ratio 3.92 (1.55$10.11)$ and 11.56 (2.38-76.39) respectively (Fig. 1). If the HDV RNA was detectable at 24 weeks, positive predictive value (PPV) for a detectable RNA at end of treatment was 0.76 (0.54-0.85) and negative predictive value (NPV) 0.56 (0.47-0.63). This PPV further increased to $0.95(0.85-0.99)$ for a detectable PCR at 6 months post treatment and NPV decreased to 0.36 (0.29-0.39). End of treatment biological response i.e. normal ALT at the end of treatment was also a predictor of ETR and SVR $(p=0.004$ and 0.041 , risk ratio $1.90(1.17-2.96)$ and $2.05(0.95-4.45)$, odds ratio 3.29 (1.32-8.25) and 2.60 (0.93-7.32) respectively.

Among 80 patients, who could not achieve SVR, 58 were non responders which included 7 breakthroughs i.e. negative PCR at 24 weeks and detectable HDV RNA at 48 weeks. Three patients had undetectable HDV RNA at 24 weeks but were lost to follow up between 24 to 48 weeks of treatment and were considered non-responders in the intention to treat analysis. The rests of the non responders were 'null' responders including 3 out of 4 patients who decompensated during treatment. Twenty-two patients had end of treatment virological response but relapsed. This figure included two patients were lost to follow up after completion of treatment.

Considering patients who completed 48 weeks of therapy $(n=98)$ after excluding dropouts $(n=3)$ and therapy discontinuation due to decompensation $(n=3)$, the end of treatment virological response was seen in 45\% (44/98) and biochemical response in 39\% (38/98). Mean ALT was $49.2 \pm 24.8$ in responders and $83.0 \pm 60.5$ in non-responders $(p=0.000)$. Sustained virological response who completed the study according to the protocol and the follow-up $(n=96)$ was $25 \%$ (24/96), biochemical response 25\% (24/96) and a combined response in 13/96 (13.5\%). Mean ALT in patients with SVR was $51.6 \pm 60.3$ and in patients without SVR $92.8 \pm 75.8(p=0.028)$

The side effects reported by these patients were usually of PEG-IFN and included nausea, weakness, fever, bloating, decreased appetite, body aches, headaches, weight loss. These side effects did not require a dose reduction. Significant thrombocytopenia was seen in 6 patients, which required interruption of therapy for 2 weeks in 2 cases, and dose reduction in the rest for 3-4 weeks. One patient received interleukin-11 as well, to increase the platelet count. One patient developed significant neutropenia and was given filgrastim. Four patients decompensated; 3 during the treatment after 24 weeks of therapy and one during the follow-up period. All were male and had an age of 32, 40, 40 and 45 years. They were having clinical cirrhosis at the time of initiation of treatment but fulfilled the inclusion criteria. The patient who deompensated during the follow-up period had sustained virological response, while rest of three were non-responders. 


\section{DISCUSSION}

So far, interferon alpha, standard or pegylated, is the only treatment option for hepatitis D. In a systematic meta-analysis, standard interferon alpha led to the end of treatment virological response in $32.6 \%$ of the patients compared with $7.8 \%$ in the untreated controls [4]. Sustained virological response was achieved in $17.4 \%$ of patients on interferon compared with $5.2 \%$ of controls. PEG-IFN is considered superior to conventional interferon. However, a head to head comparison of PEG-IFN with standard interferon has not been done. The pilot studies using PEGIFN alpha-2b (1.5 $\mu \mathrm{g}$ per kilogram of body weight per week) for periods of 48 to 72 weeks showed a sustained virological response 6 months after the end of treatment in 17 to $43 \%$ of the treated patients [6-8]. The results of HIDIT-1 trial showed that treatment with PEG-IFN alpha-2a for 48 weeks, with or without adefovir, resulted in sustained HDV RNA clearance in about one quarter of patients with HDV infection [9]. All these trials were done in a controlled setting. We have gathered here the response in the real world scenario while treating these patients in clinics. Our experience is not much different from the published clinical trials.

The incidence of HDV infection in the West is decreasing but the infection is still very much prevalent in our country [10]. Though the prevalence of HBsAg positivity is $2.5 \%$, there are certain districts with much higher prevalence. This "hepatitis belt" also has the highest prevalence of HDV super infection and represents a serious public health problem $[11,12]$. So we were able to get enough patients to offer treatment and compile this data.

It has been documented previously that despite low rates of eradication of the virus, standard interferon may favorably affect the natural history of the disease in the long run [13]. We witnessed normalization of ALT in a significant number of patients treated with pegylated interferon even without virological response (Fig. 1). The ultimate goal of treatment should be the eradication of $\mathrm{HBsAg}$ which is difficult to achieve as none of our patients became HBsAg negative.

We followed up our patients only for 24 weeks post treatment and found a sustained response of $23 \%$. From our experience of treating hepatitis $\mathrm{C}$ with interferon, the possible factors that may influence the outcome of treatment in case of hepatitis $D$ could also be genotype and viral load, rapid virological response, stage of fibrosis, duration of disease, previous treatment, duration of therapy, compliance and IL28B polymorphism. The genotype of HBV and baseline HBsAg level might also be the possible predictors. Apparently, hepatitis D behaves in a different way from hepatitis $C$. We tried to find out factors leading to sustained virological response in our patients. The genotype of hepatitis $D$ is 1 [14] and of hepatitis $B$ virus is $D$ [15] in our province so these factors could not confound our results. Role of HBsAg titer in predicting response has not been established [9]. Presence of absence of cirrhosis, degree of inflammation, and stage of 
fibrosis did not influence the outcome in our study. Kabaçam $\mathrm{G}$ et al also found that response rate to pegylated interferon is same in patients with or without advanced liver disease [16]. Studies have shown that measuring HDV RNA at 24 weeks of therapy and documenting 2-3 log reduction may be of help in predicting response $[6-8,17]$. As we did not have the baseline viral load available in all patients we relied on qualitative PCR which was done in all cases at 24 weeks. Negative HDV RNA was a strong predictor of sustained virological response in our study (risk ratio7.75 (1.98-47.16) If the HDV RNA was detectable at 24 weeks, positive predictive value (PPV) for a detectable RNA at 6 months post treatment was $0.95(0.85-0.99)$ and a negative predictive value of $0.36(0.29-0.39)$. This means that patients who still harbor HDN RNA in their blood at 24 weeks of treatment are less likely to have SVR, and at the same time negative PCR at 24 weeks does not guarantee an SVR.

The strength of the study is that it included a reasonable number of patients and the sample size is much larger than many previous studies. This study tells us the response rate and compliance in the real world scenario which was not worse than the controlled settings. The shortcomings of this study were that all the baseline parameters done in controlled trials could not be done in all patients including quantitative PCR, genotype, and pre-treatment biopsies. The patients were followed up for only 24 weeks after treatment and long term follow-up were not available to predict sustained response later on.

In conclusion, treatment with pegylated interferon for hepatitis $D$ is of limited efficacy. It is difficult to expect who would respond to the treatment. A detectable HDV RNA at 24 weeks of treatment is a good predictor for a failed sustained virological response.

\section{Acknowledgements and disclosures}

This study was not funded by any agency. There are no conflicts of interest to disclose relevant to this article

\section{References:}

1. Pascarella S, Negro F. Hepatitis D virus: an update. Liver Int 2011; 31:7-21.

2. Romeo R, Del Ninno E, Rumi M, et al. A 28-year study of the course of hepatitis Delta infection: a risk factor for cirrhosis and hepatocellular carcinoma. Gastroenterology 2009; 136:1629-1638.

3. Wedemeyer H. Hepatitis D revival. Liver Int 2011; 31 Suppl 1:140-144.

4. Abbas Z, Khan MA, Salih M, Jafri W. Interferon alpha for chronic hepatitis $D$. Cochrane Database Syst Rev 2011; 12:CD006002.

5. Batts KP, Ludwig J. Chronic hepatitis. An update on terminology and reporting. Am J Surg Pathol 1995; 19:1409-1417.

6. Erhardt A, Gerlich W, Starke C, et al. Treatment of chronic hepatitis delta with pegylated interferon-alpha2b. Liver Int 2006; 26:805-810.

7. Castelnau C, Le Gal F, Ripault MP, et al. Efficacy of peginterferon alpha-2b in chronic hepatitis delta: relevance of quantitative RT-PCR for follow-up. Hepatology 2006; 44:728-735. 
Publication: Antiviral Therapy; Type: Original article

DOI: $10.3851 / \mathrm{IMP} 2728$

8. Niro GA, Ciancio A, Gaeta GB, et al. Pegylated interferon alpha-2b as mono- therapy or in combination with ribavirin in chronic hepatitis delta. Hepatology 2006; 44:713-720.

9. Wedemeyer $\mathrm{H}$, Yurdaydìn C, Dalekos GN, et al. Peginterferon plus adefovir versus either drug alone for hepatitis delta. N Engl J Med 2011; 364:322-331.

10. Abbas Z, Jafri W, Raza S, Hepatitis D. Scenario in the Asia-Pacific region. World $J$ Gastroenterol 2010; 16:554-562.

11. Seetlani NK, Abbas Z, Raza S, Yakoob J, Jafris W. Prevalence of hepatitis D in HBsAg positive patients visiting liver clinics. J Pak Med Assoc 2009; 59:434-437.

12. Mumtaz K, Hamid SS, Adil S, et al. Epidemiology and clinical pattern of hepatitis delta virus infection in Pakistan. J Gastroenterol Hepatol 2005; 20:1503-1507.

13. Farci $P$, Mandas A, Coiana A, et al. Treatment of chronic hepatitis D with interferon alfa2a. N Engl J Med 1994; 330:88-94.

14. Moatter T, Abbas Z, Shabir S, Jafri W. Clinical presentation and genotype of hepatitis delta in Karachi. World J Gastroenterol 2007; 13:2604-2607.

15. Abbas Z, Muzaffar R, Siddiqui A, Naqvi SA, Rizvi SA. Genetic variability in the precore and core promoter regions of hepatitis B virus strains in Karachi. BMC Gastroenterol 2006; 6:20.

16. Kabaçam G, Dalekos GN, Çakaloğlu Y, et al. Pegylated interferon-based treatment in patients with advanced liver disease due to chronic delta hepatitis. Turk J Gastroenterol 2012; 23:560-568.

17. Yurdaydin C, Bozkaya $\mathrm{H}$, Onder FO, et al. Treatment of chronic delta hepatitis with lamivudine vs lamivudine + interferon vs interferon. J Viral Hepat 2008; 15:314-321. 
Publication: Antiviral Therapy; Type: Original article

DOI: $10.3851 / \mathrm{IMP} 2728$

Table 1: Baseline characteristics of the study patients

\begin{tabular}{|l|l|}
\hline Characteristics & $30.1 \pm 10.0$ \\
\hline $\begin{array}{c}\text { Age-years } \pm \text { S.D. } \\
\text { median (range) }\end{array}$ & $30.0(15-55)$ \\
\hline Male gender & $91(87.5 \%)$ \\
\hline Body mass index $\left(\mathrm{kg} / \mathrm{m}^{2}\right)$ & $23.5 \pm 5.02$ \\
\hline Palpable liver & $28(26.9 \%)$ \\
\hline Palpable spleen & $30(28.8 \%)$ \\
\hline $\begin{array}{l}\text { Cirrhosis (clinical / biopsy } \\
\text { /ultrasound) }\end{array}$ & $41(39.4 \%)$ \\
\hline Hemoglobin (g/dl) & $13.5 \pm 1.9$ \\
\hline TLC $\left(\times 10^{6} / \mathrm{L}\right)$ & $6.5 \pm 2.6$ \\
\hline Platelets $\left(\mathrm{x} 10^{9} / \mathrm{L}\right)$ & $186 \pm 72$ \\
\hline Bilirubin (mg/dl) & $0.94 \pm 0.78$ \\
\hline ALT (IU/L) & $114 \pm 100$ \\
\hline GGT(IU/L) & $92 \pm 98$ \\
\hline Alkaline phosphatase (IU/L) & $152 \pm 88$ \\
\hline HBeAg-positive patients (\%) & $29(27.9 \%)$ \\
\hline HBV DNA detected & $37(35.6 \%)$ \\
\hline
\end{tabular}

$\mathrm{ALT}$, alanine aminotransferase; GGT, gamma glutamyl transferase; HBeAg, hepatitis B e antigen; HBV, hepatitis $B$ virus; RNA, ribonucleic acid 
Publication: Antiviral Therapy; Type: Original article

DOI: $10.3851 / \mathrm{IMP} 2728$

Table 2: Factors associated with sustained virological response (SVR) six months post treatment

\begin{tabular}{|c|c|c|c|}
\hline Factor & $\begin{array}{l}\text { SVR positive } \\
(n=24)\end{array}$ & $\begin{array}{l}\text { SVR Negative } \\
(\mathrm{n}=80)\end{array}$ & p value \\
\hline Age (years \pm S.D.) & $33.7 \pm 9.2$ & $30.0 \pm 10.2$ & 0.111 \\
\hline Male gender & 22 & 69 & 0.728 \\
\hline Body mass index $\left(\mathrm{kg} / \mathrm{m}^{2}\right)$ & $23.8 \pm 3.8$ & $23.4 \pm 5.6$ & 0.759 \\
\hline Cirrhosis & 07 & 34 & 0.341 \\
\hline Platelets $\left(\times 10^{9} / \mathrm{L}\right)$ & $191 \pm 89$ & $184 \pm 66$ & 0.719 \\
\hline Baseline ALT (IU/L) & $127 \pm 135$ & $110 \pm 87$ & 0.458 \\
\hline Baseline GGT (IU/L) & $89 \pm 80$ & $94 \pm 105$ & 0.901 \\
\hline HBeAg Reactive & 05 & 24 & 0.380 \\
\hline HBV DNA detected & 09 & 28 & 0.813 \\
\hline $\begin{array}{l}\text { Severe Inflammation } \\
\text { (Biopsy in } 39 \text { patients) }\end{array}$ & 07 & 19 & 1.000 \\
\hline $\begin{array}{l}\text { Advanced fibrosis } \\
\text { (Biopsy in } 39 \text { patients) }\end{array}$ & 02 & 07 & 1.000 \\
\hline $\begin{array}{l}\text { HDV RNA level }\left(\times 10^{6} \mathrm{IU} / \mathrm{ml}\right)(\mathrm{n} \\
=30)\end{array}$ & $11.6 \pm 15.9$ & 7. \pm 14.4 & 0.464 \\
\hline $\begin{array}{l}\text { Pegylated interferon alpha-2a } \\
\text { Pegylated interferon alpha- } 2 \mathrm{~b}\end{array}$ & $\begin{array}{l}15 \\
09\end{array}$ & $\begin{array}{l}54 \\
26\end{array}$ & 0.649 \\
\hline $\begin{array}{l}\text { Negative HDV RNA at } 24 \\
\text { weeks }\end{array}$ & 33 & 26 & 0.001 \\
\hline ALT at 24 weeks & $63 \pm 40$ & $75 \pm 43$ & 0.283 \\
\hline Normal ALT at 48 weeks & 13 & 25 & 0.041 \\
\hline $\begin{array}{l}\text { Negative HDV RNA at } 48 \\
\text { weeks }\end{array}$ & 22 & 22 & 0.000 \\
\hline
\end{tabular}

ALT, alanine aminotransferase; GGT, gamma glutamyl transferase; HBeAg, hepatitis $\mathrm{B}$ e antigen; HBV, hepatitis $B$ virus; HDV, hepatitis D virus; RNA, ribonucleic acid

Fig 1: Week 24 HDV RNA (Wk 24 PCR) and normalization of alanine aminotransferase (ALT) at the end of treatment (Wk 48 ALT) predicting the end of treatment virological response (ETR) and sustained virological response (SVR) 


\section{Wk 24 PCR and ETR}

Wk 24 PCR positive Wk 24 PCR negative

$p=0.001$

33

34

11

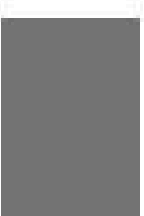

ETR achieved

ETR not achieved

\section{Wk 24 PCR and SVR}

Wk 24 PCR positive $\quad$ Wk 24 PCR negative

$p=0.000$

41

39

22

2

SVR achieved

SVR not achieved

\section{Wk 48 ALT and SVR}

Wk 48 ALT elevated Wk 48 ALT normal

$p=0.041$

55

$p=0.004$

45

15

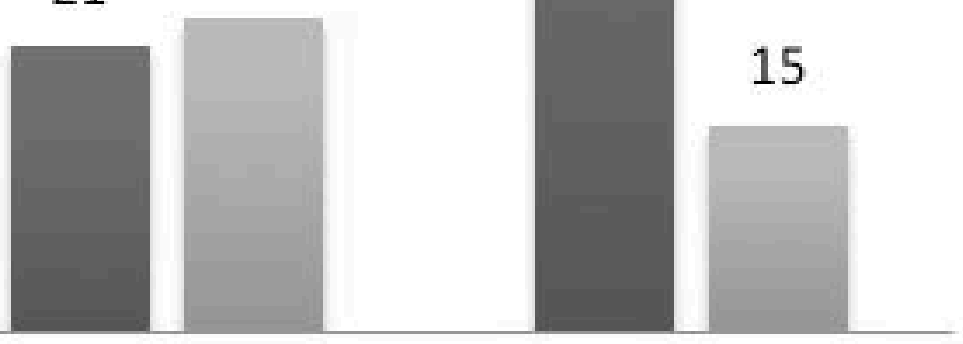

ETR achieved

ETR not achieved

25

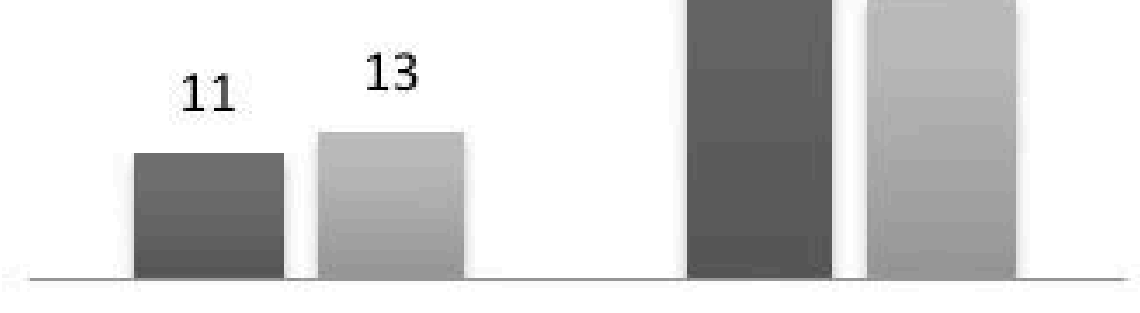

SVR achieved 